\title{
Neuromyelitis Optica: A Mini Review
}

\author{
Taru Dewan* and Nidhi Sharma \\ Department of Ophthalmology, Dr. Ram Manohar Lohia Hospital, India
}

Submission: October 03. 2017; Published: November 13, 2017

*Corresponding author: Taru Dewan, Department of Ophthalmology, Post Graduate Institute of Medical Education and Research, Dr. Ram Manohar Lohia Hospital, New Delhi-110001, India, Tel: 9810673180; Email: tarudewan@hotmail.com

\begin{abstract}
Neuromyelitis optica (NMO) is an idiopathic inflammatory disorder affecting the central nervous system. Previously thought to be related to Multiple sclerosis NMO recently came out to be a distinct clinical identity with new diagnostic criteria and physical tests. Broader understanding and confirmatory assay for anti- aquaporin- 4 antibodies have changed the diagnostic and treatment protocol for the disease. It carries a significant mortality and morbidity. Newer modalities of treatments for acute exacerbations and for relapses have come up with better understanding. This review describes some of the new findings, clinical manifestations, biomarkers associated with the disease and magnetic resonance imaging characteristics.
\end{abstract}

Keywords: NMO; MRI; NMOSD; Anti-aquaporin 4 IGg; TM

Abbreviations: NMO: Neuromyelitis Optica; NMOSD: Neuromyelitis Optica Spectrum Syndrome; MRI: Magnetic Resonance Imaging; Anti-AQ4 IgG: Anti Aquaporin-4 Immunoglobulin; SLE: Systemic Lupus Erythemaotosis; ANCA: Anti-Neutrophilic Cytoplasmic Antibody; TM: Transverse Myelitis; CSF: Cerebrospinal Fluid; AION: Anterior Ischaemic Optic Neuropathy; PION: Posterior Ischaemic Optic Neuropathy

\section{Introduction}

Neuromyelitis optica (NMO) is a severe idiopathic immunemediated necrotizing and demyelinating disease that mainly involves the spinal cord and optic nerve [1]. The target antigen is aquaporin- 4 , the dominant water channel in central nervous system, found in the astrocyte foot processes at the blood-brain barrier [2]. A number of conditions were discovered with antiAQ4 IgG necessitating coining of the term Neuromyelitis Optica Spectrum of disorders [3]. Antibodies against aquaporin-4 differentiate it from Multiple sclerosis [4].

As NMO carries significant morbidity and mortality, early diagnosis with quick initiation of therapy in the form of corticosteroids, plasma exchange helps in proper management.

\section{Discussion}

In India, there is scarcity of epidemiological data for demyelinating disorders. Predominantly females are involved with a mean age of onset 32.6- 45.7 years and median time to first relapse is 8- 12 months [5].

In Indian population an association of HLA-DRB1*03 [6] with NMO has been found which is supported with evidence from Brazil [7], the Carribean Islands [8] and France [9]. It may be associated with other systemic autoimmune disorders like SLE, Sjogren's syndrome or p-ANCA associated vasculitis. Sometimes onset may be associated with acute infection like varicella zoster or HIV.

\section{Clinical Manifestations}

Longitudinally Extensive Transverse Myelitis (LETM) defined as longitudinal cord lesions extending in more than three vertebral segments and acute severe optic neuritis are classical features of NMO [3]. The core features of NMO include optic neuritis, acute myelitis, area postrema syndrome, acute brainstem syndrome, symptomatic narcolepsy or acute diencephalic clinical syndrome and symptomatic cerebral syndrome [1]. In $15-40 \%$ of cases there is concomitant occurrence of both optic neuritis and transverse myelitis [3]. Severe visual impairment, bilateral simultaneous or sequential optic neuritis in rapid succession with poor recovery with visual acuity of $20 / 200$ or worse $[10,11]$ and non central scotoma deficits such as altitudinal field defects should raise suspicion for NMOSD [12]. Classical tumefactive and longitudinal lesions in MRI may be missed in early course of disease and during resolution phase [13]. MRI findings of posterior optic nerve 
involvement particularly chiasm is highly suggestive of NMO. Other common findings are neuropathic pain, Lhermittes sign and painful tonic spasms [14].

\section{Laboratory Testing}

Suspected patients should be evaluated for anti- aquaporin-4 antibodies. Cell based assay is preferred over tissue based assay or ELISA because of higher sensitivity and specificity [15]. CSF analysis is not mandatory and only indicated in doubtful cases. CSF findings are dependent on activity status of the disease. In acute stages WBC count (>380cells/ul) [16], glial fibrillary acidic protein, serum proteins mainly albumin $[16]$ and IL-6 $[17,18]$ are raised.

\section{Differential Diagnosis}

It includes infectious causes like bacterial and viral, reactive causes like post infectious, vascular like AION, PION, nutritional causes like vitamin deficiency, tobacco consumption, compressive lesions like ocular tumors, familial and hereditary causes. Differentials of TM are spinal infarction, fistulas, compressive lesions, B 12 deficiency, paraneoplastic syndromes, multiple sclerosis and infections [1].

\section{Treatment}

Corticosteroids and plasma exchange are most commonly employed therapies for acute exacerbations. IV immunoglobulins may also be used [1].

\section{Corticosteroids}

Acute exacerbations are treated with IV methylprednisolone $1 \mathrm{~g} /$ day for 5 days followed by prolonged prednisolone taper for 2 to 6 months [1].

\section{Plasma exchange}

Considered as first line therapy in patients not responding to steroid therapy or in patients who were successfully treated with plasma exchange previously. Typical protocol is an exchange of 1 to 1.5 volumes of plasma every other day for a total of five treatments [1].

\section{IV immunoglobulins}

Suggested in patients with no response or contraindication to corticosteroids or plasma exchange [1].

\section{Conclusion}

NMO is an inflammatory disorder with high mortality and morbidity so early recognition of disease offers a window of opportunities for treatment and induction of remission.

\section{References}

1. Pandit L (2015) Neuromyelitis optica spectrum disorders: An update. Ann Indian Acad Neurol 18(Suppl 1): S11-S15.
2. Hinson SR, Pittock SJ, Lucchinetti CF, Roemer SF, Fryer JP, et al. (2007) Pathogenic potential of IgG binding to water channel extracellular domain in neuromyelitis optica. Neurology 69(24): 2221-2231.

3. Katz Sand I (2016) Neuromyelitis Optica Spectrum Disorders. Continuum (Minneap Minn) 22(3): 864-896.

4. Lana-Peixoto MA (2008) Devic's neuromyelitis optica: a critical review. Arq Neuro-Psiquiatr 66(1): 120-138.

5. Pandit L, Asgari N, Apiwattanakul M, Palace J, Paul F, et al. (2015) Demographic and clinical features of neuromyelitis optica: A review. Mult Scler 21(7): 845-853.

6. Pandit L, Malli C, D'Cunha A, Mustafa S (2015) Human leukocyte antigen association with neuromyelitis optica in a south Indian population. Mult Scler 21(9): 1217-1218.

7. Brum DG, Barreira AA, dos Santos AC, Kaimen-Maciel DR, Matiello M, et al. (2010) HLA-DRB association in neuromyelitis optica is different from that observed in multiple sclerosis. Mult Scler 16(1): 21-29.

8. Deschamps R, Paturel L, Jeannin S, Chausson N, Olindo S, et al. (2011) Different HLA class II (DRB1 and DQB1) alleles determine either susceptibility or resistance to NMO and multiple sclerosis among the French Afro-Caribbean population. Mult Scler 17(1): 24-31.

9. Zéphir H, Fajardy I, Outteryck O, Blanc F, Roger N, et al. (2009) Is neuromyelitis optica associated with human leukocyte antigen? Mult Scler 15(5): 571-579.

10. Lim YM, Pyun SY, Lim HT, Jeong IH, Kim KK (2014) First-ever optic neuritis: distinguishing subsequent neuromyelitis optica from multiple sclerosis. Neurol Sci 35(5): 781-783.

11. Wingerchuk DM, Hogancamp WF, O'Brien PC, Weinshenker BG (1999) The clinical course of neuromyelitis optica (Devic's syndrome). Neurology 53(5): 1107-1114.

12. Nakajima H, Hosokawa T, Sugino M, Kimura F, Sugasawa J, et al. (2010) Visual field defects of optic neuritis in neuromyelitis optica compared with multiple sclerosis. BMC Neurol10: 45.

13. Flanagan EP, Weinshenker BG, Krecke KN, Pittock SJ (2015) Asymptomatic myelitis in neuromyelitis optica and autoimmune aquaporin-4 channelopathy. Neurol Clin Pract 5(2): 175-177.

14. Kim SM, Go MJ, Sung JJ, Park KS, Lee KW (2012) Painful tonic spasm in neuromyelitis optica: incidence, diagnostic utility, and clinical characteristics. Arch Neurol 69(8):1026-1031.

15. Ruiz-Gaviria R, Baracaldo I, Castañeda C, Ruiz-Patiño A, AcostaHernandez A, et al. (2015) Specificity and sensitivity of aquaporin 4 antibody detection tests in patients with neuromyelitis optica: A metaanalysis. Mult Scler Relat Disord 4(4): 345-349.

16. Jarius S, Paul F, Franciotta D, Ruprecht K, Ringelstein M, et al. (2011) Cerebrospinal fluid findings in aquaporin-4 antibody positive neuromyelitis optica: results from 211 lumbar punctures. J Neurol Sci 306(1-2): 82-90.

17. Uzawa A, Mori M, Sawai S, Masuda S, Muto M, etal. (2013) Cerebrospinal fluid interleukin- 6 and glial fibrillary acidic protein levels are increased during initial neuromyelitis optica attacks. Clin Chim Acta 421: 181183.

18. Uzawa A, Mori M, Ito M, Uchida T, Hayakawa S, et al. (2009) Markedly increased CSF interleukin-6 levels in neuromyelitis optica, but not in multiple sclerosis. J Neurol 256(12): 2082-2084. 
CC (i) This work is licensed under Creative Commons Attribution 4.0 License DOI: $10.19080 / J 0 J 0.2017 .05 .555663$
Your next submission with Juniper Publishers will reach you the below assets

- Quality Editorial service

- Swift Peer Review

- Reprints availability

- E-prints Service

- Manuscript Podcast for convenient understanding

- Global attainment for your research

- Manuscript accessibility in different formats

( Pdf, E-pub, Full Text, Audio)

- Unceasing customer service

Track the below URL for one-step submission https://juniperpublishers.com/online-submission.php 